\title{
Article
}

\section{Development of the Application of Magnetic Microsorbents for the Elimination of Hazardous Inorganic Contaminants from Natural Waters}

\author{
Thomas DAHLKE, Matthias FRANZREB, Wolfgang H. HÖLL \\ Karlsruhe Research Centre, Institute of Technical Chemistry, Section WGT, P.O. Box 3640, D-76021 Karlsruhe
}

(Manuscript submitted January 21, 2003; accepted April 7, 2003)

\begin{abstract}
Magnetic, weakly basic anion exchangers with particle diameters between $100 \mu \mathrm{m}$ and $250 \mu \mathrm{m}$ were synthesised for the uptake of heavy metals from waste water or natural waters. These resins were investigated basically, including sorption equilibria and kinetics. Afterwards, the selective removal of copper and zinc was demonstrated in a continuously operating pilot plant, including regeneration and recycling of the resin. Experiments were carried out at different metal concentrations $\left(2 \mathrm{mg} / \mathrm{dm}^{3}\right.$ to $10 \mathrm{mg} /$ $\mathrm{dm}^{3}$ ) and flow rates between $100 \mathrm{dm}^{3} / \mathrm{h}$ and $400 \mathrm{dm}^{3} / \mathrm{h}$. For the evaluation of the process a theoretical model was developed. The calculations were confirmed by the experimental results.
\end{abstract}

\section{Introduction}

The removal of heavy metals by weakly basic anion exchangers is based on the Lewis acid-base interaction theory. Several projects have shown that the selective removal of heavy metals like copper, zinc, cadmium or lead is possible by the simultaneous sorption of the metal cation and a respective anion like sulphate.[3] A principle advantage of this sorption process is that the matrix of the treated water hardly shows any alteration. This means that either no other cations like calcium or magnesium are taken up or that no other ions will be released from the resin functional groups. Unfortunately, the kinetics of this sorption process are slow so that commercially available anion exchange resins with particle diameters of about $800 \mu \mathrm{m}$ are of limited use. If smaller prototypes of the resins are produced, the problem arises that they cannot be used in fixed-bed columns due to the high pressure drop which would occur. These reasons exemplify why this type of ion exchanger has only rarely been used for the removal of heavy metals.

In the last decades, CSIRO molecular science, Clayton (Australia) developed small-size ion exchangers with a magnetic core.[1] The magnetic ion exchanger (MIEX®) is used for NOM removal [2] and commercially available in Australia and the United States already. The particles have a diameter ranging from $100 \mu \mathrm{m}$ to 250 $\mu \mathrm{m}$. Due to the small particle diameter, the ion exchange kinetics are quick, making them suitable for usage in a continuous process. Another advantage caused by the magnetic properties is that if the particles settle, they agglomerate into larger flocs. This results in settling velocities much higher than for the single particles. The idea of the project described in this paper was to combine the advantages of selective heavy metal removal by sorption on weakly basic anion exchangers and of the fast kinetics and easy handling of small magnetic ion exchange resins.

For this purpose, the MIEX resin was functionalised with weakly basic groups. In the basic experiments 
adsorption equilibria were investigated to determine the selectivity of the resin. In addition, batch kinetic experiments and particle size distribution measurements were conducted. After the basic investigations with several amines that were functionalised onto the resin, an adsorption pilot plant was designed and set up.

The paper presents the results of the copper isotherm, regeneration, the pilot plant experiments, and the first improvements that were introduced in the process. Furthermore, the experimental results will be compared with theoretical calculations based on a simplified kinetic approach and the derived equilibrium data.

\section{Experimental}

\subsection{Experimental setup of the pilot plant}

The experiments were carried out with the pilot setup shown in Fig. 1. From the water storage tank (1) the water was pumped to a CSTR which served as contactor (2). A solution containing dissolved heavy metal salt was added before the water flew into the contactor (8). After passing the CSTR, the treated water was separated from the resin in a conical settler (3). The water was pumped back to the storage tank, while the resin was transferred to the regenerator (4). The regeneration chemicals (6) were added in two consecutive steps. In the first step sulphuric acid was added to remove the metal ions, in the second step sodium hydroxide was used to neutralise the exchanger. The chemicals were drained from the vessel by a valve (7). Finally, the regenerated resin was pumped back into the resin storage tank (5) before being added again into the contactor. Samples were taken upstream and downstream of the heavy metal salt addition as

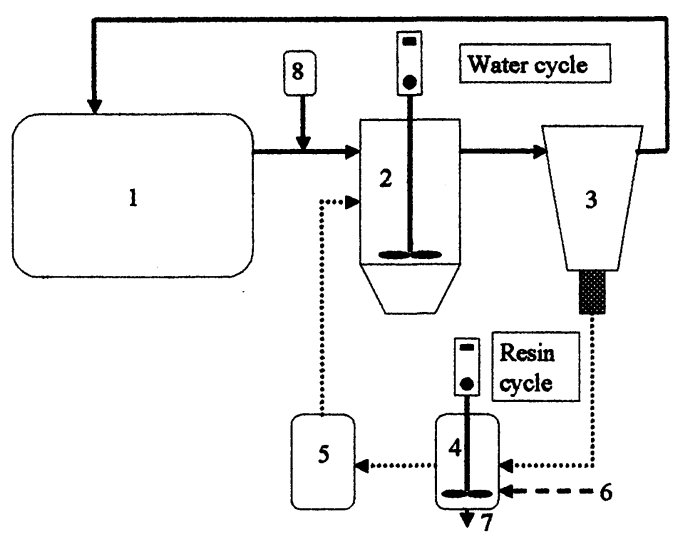

Fig. 1 Basic flowsheet of the adsorption process well as at the contactor outlet. The process was controlled by a PL device, and a computer visualisation was used to record $\mathrm{pH}$ and conductivity in all vessels and to check the state of the process. The pilot plant could operate either in a fully automatic mode or by manual control. The pumps and valves used are not depicted in Fig. 1.

\subsection{Experimental procedure (pilot plant)}

The experiments were carried out as follows. First, resin suspension was pumped into the contactor until it contained a resin mass which corresponded to the estimated steady-state conditions. Then, while continuing the resin dosage, the water cycle was started. After $\mathrm{pH}$ and conductivity had reached steady values, dosage of the heavy metal-containing solution was switched on. Samples were taken every 30 minutes at all three places described above. In addition to the samples in the water cycle, one sample was taken from the regeneration acid. The pilot plant contactor was stirred at $200 \mathrm{rpm}$ with an Ekato INTERMIG stirrer. Regeneration was carried out in a $12 \mathrm{~L}$ glass vessel with diluted sulphuric acid at a pH of 2 and diluted $\mathrm{NaOH}$ at a pH between 9 and 10 .

\subsection{Other experiments}

The aqueous samples were analysed with standard AAS and ICP methods. For the determination of the copper isotherm, $0.5 \mathrm{~g}$ resin in the free base form and $3 \mathrm{~mL} \mathrm{H}_{2} \mathrm{SO}_{4}(0.1 \mathrm{M})$ were added to several glass beakers containing different amounts of $\mathrm{CuSO}_{4}$ dissolved in $60 \mathrm{~mL}$ distilled water. Because of the fast kinetics, an equilibrium was reached within $90 \mathrm{~min}$ and the copper loading could be calculated from the measured copper concentration by means of a mass balance.

To demonstrate the regeneration efficiency, $1.5 \mathrm{~g}$ of a copper-loaded resin were regenerated in small columns. This was done using $0.5 \mathrm{M} \mathrm{HCl}$. The acid was collected in volumetric flasks after it had been contacted 
with the resin. The concentration was determined with the standard procedures mentioned above.

\section{Results and discussion}

\subsection{Resin characterisation and particle properties}

The particles used for the experiments described in the following section were macroporous, magnetic weakly basic anion exchangers. They consisted of a magnetic core (maghemite) coated by a polymer. The mean particle diameter was $200 \mu \mathrm{m}$ and the dry density $0.31 \mathrm{~g} / \mathrm{cm}^{3}$.

For the characterisation of the sorption properties with respect to heavy metals, an isotherm was determined for copper sulphate. As expected according to Fig. 3, copper loading increased rapidly with increasing equilibrium copper concentration in the solution. However, for copper concentrations higher than $10 \mathrm{mmol} / \mathrm{dm}^{3}$, the measured copper loading started to decrease. The reason for this is that the experiments were not conducted under stationary $\mathrm{pH}$ conditions. In case of small amounts of $\mathrm{CuSO}_{4}$ added $\left(<10 \mathrm{mmol} / \mathrm{dm}^{3}\right)$, the equilibrium $\mathrm{pH}$ was constant at $\mathrm{pH}=4.8$. For higher amounts the equilibrium $\mathrm{pH}$ dropped to $\mathrm{pH}=4.1$ at $\mathrm{c}_{\mathrm{Cu}}{ }^{*}=56 \mathrm{mmol} / \mathrm{dm}^{3}$ because of the acid nature of $\mathrm{CuSO}_{4}$. From this it can be seen that sorption of $\mathrm{H}^{+}$is strongly preferred to that of $\mathrm{Cu}^{2+}$ and the $\mathrm{pH}$ of the feed solution will strongly influence the sorption equilibria. The regeneration experiments depicted in Fig. 2 show the behaviour of the acid regeneration curve and the release of iron into the acid by dissolving the iron oxide in the particle. It can be seen that the regeneration peaks between 10 and 20 bed volumes (BV). Comparing the amount of metal loaded on the resin with the amount found in the acid, an efficiency of $93 \%$ results. The iron release of the resin was almost zero, so that it can be concluded that the polymer protects the iron oxide core sufficiently. In the experiments carried out in the pilot plant, regeneration was performed with sulphuric acid due to the corrosivity of highly concentrated $\mathrm{HCl}$.

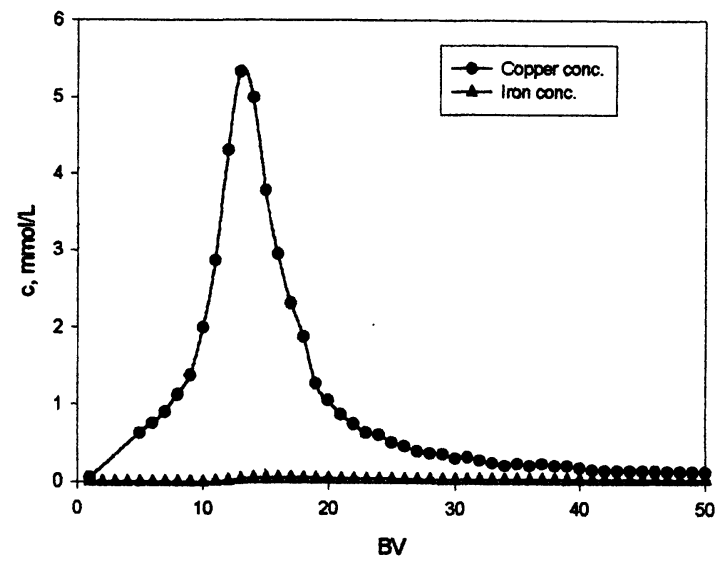

Fig. 2 Regeneration of a Cu-loaded MIEX resin and iron release of the beads

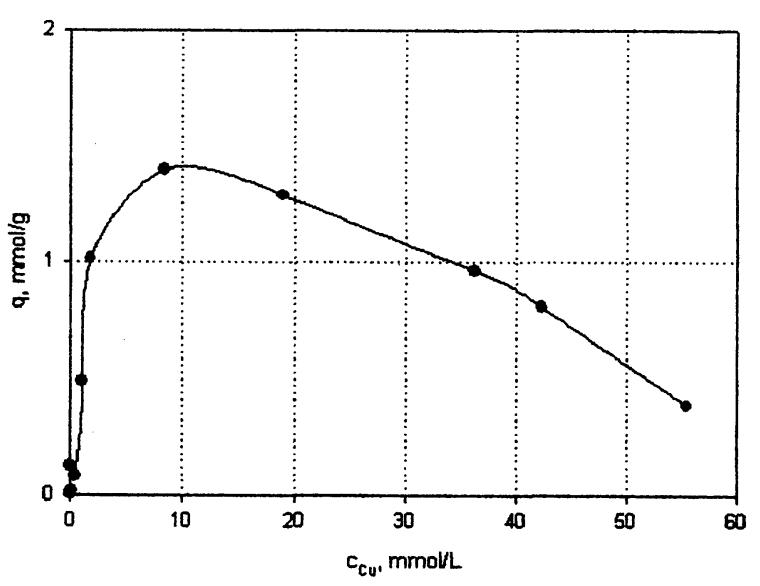

Fig. 3 Adsorption isotherm for the MIEX resin on copper sulphate

\subsection{Pilot plant experiments (Cu removal)}

The pilot plant experiments were carried out at a stirrer speed of $200 \mathrm{rpm}$ in the contactor. It was shown in previous experiments with the resin beads that the mass transfer rate was not influenced significantly by the stirrer speed, so that the selected revolutions guaranteed a well-mixed water-particle suspension. The regeneration time was also investigated and optimised to 5 minutes for acid and 1 minute for $\mathrm{NaOH}$. The regeneration efficiency for this time span was approximately $75 \%$.

The experiments were performed by varying the solution feed rates or the particle concentration and flow 
rate of the resin suspension, respectively. Figures 4 and 5 show the results of the experiments as well as the theoretical plots in the form of the dimensionless effluent concentrations as a function of operating time. Figure 4 shows the influence of the variation of the solution feed rate to the CSTR in the range between $200 \mathrm{dm}^{3} / \mathrm{h}$ to 400 $\mathrm{dm}^{3} / \mathrm{h}$. The initial concentration of copper in the feed solution is $5 \mathrm{mg} / \mathrm{dm}^{3}$ and the resin mass flow rate was kept constant at $20 \mathrm{~g} / \mathrm{min}$. As expected, the removal of copper improved with a decreasing feed volume rate. The steady-state value of the dimensionless effluent concentration for the $400 \mathrm{dm}^{3} / \mathrm{h}$ experiment was approximately 0.5 , while for $200 \mathrm{dm}^{3} / \mathrm{h}$ the corresponding value was below 0.3 . The $300 \mathrm{dm}^{3} / \mathrm{h}$ experiment was chracterised by a dimensionless concentration of about 0.4 . In spite of the relatively simple model, agreement between theoretical calculations and experimental results is more than satisfying. The model uses an equilibrium description by separation factors and a kinetic model based on a mass transfer limitation by the ion diffusion in a shell core system combined with the hydrodynamic behaviour of a CSTR. Details of this model are beyond the scope of this paper and will be published elsewhere.[4]

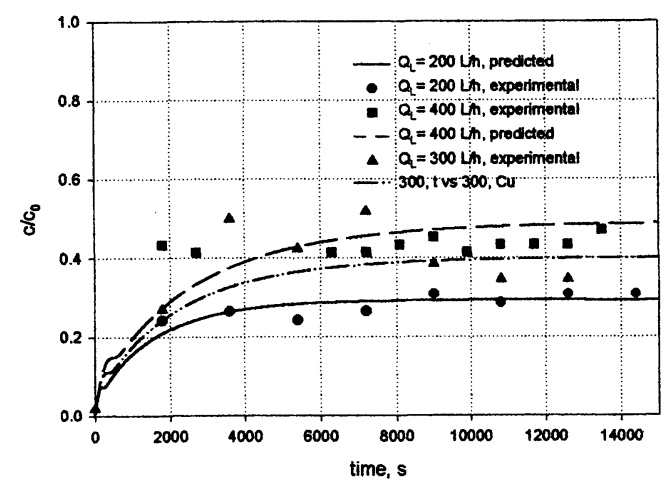

Fig. 4 Experimental results of the pilot plant with variation of the feed volume rate

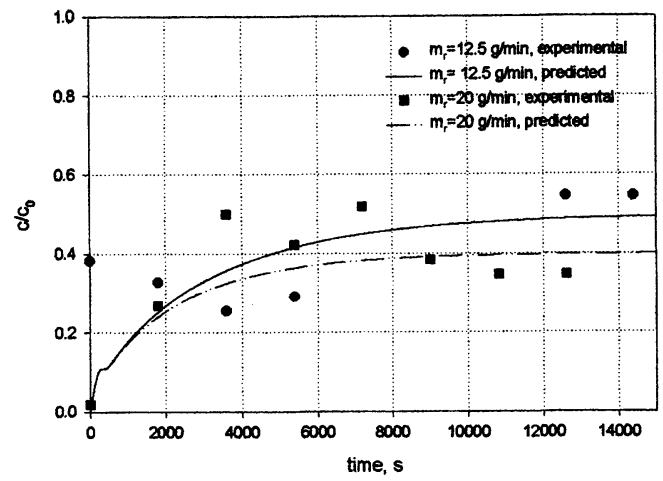

Fig. 5 Results of the experiments with the variation of the resin mass flow at a constant feed volume rate of $300 \mathrm{dm}^{3} / \mathrm{h}$

In the second set of experiments, the resin mass flow rate was varied. Two mass flows were selected: 12.5 $\mathrm{g} / \mathrm{min}$ and $20 \mathrm{~g} / \mathrm{min}$, respectively. The experiments depicted in Fig. 5 were carried out at a feed volume rate of 300 $\mathrm{dm}^{3} / \mathrm{h}$ and an initial copper concentration of $5.5 \mathrm{mg} / \mathrm{dm}^{3}$. Here, the higher resin dosage again resulted in a better copper removal, as it could be expected. From the relatively small influence of the resin dosage and the theoretical results in particular, it can be seen that copper sorption is not controlled by the kinetics, but equilibrium-limited in the system examined. Therefore, further attempts to improve the copper removal will concentrate on the synthesis of resin types of increased heavy metal selectivity first.

Later further investigations will include an optimisation of the pilot plant by the introduction of a twostep sorption process and experiments with other heavy metals like zinc.

\section{References}

1) B. Bolto, J. Ion Exchange, 4(1), 35-42 (1993).

2) M.J. Semmens, M. Burckhardt, D. Schuler, P. Davich, M. Slunjski, M. Bourke, H. Nguyen, American Water Works Conference Proceedings (2000).

3) W. H. Höll, Vom Wasser, 89, 13-24 (1997).

4) T. Dahlke, Y.-H. Chen, M. Franzreb, Wolfgang H. Höll, to be published. 